\title{
DO SUBTERRÂNEO NO HORTO: AUTA DE SOUZA E OS MITOS CULTURAIS SOBRE A POETA NO SÉCULO XIX
}

\section{LE SOUTERRAIN AU HORTO: AUTA DE SOUZA ET LES MYTHES}

CULTURELS SUR LA POÉTESSE AU XIXE SIÈCLE

Alice Vieira Barros*

* alicevieirabarros@gmail.com

Doutoranda em Teoria da Literatura e Literatura Comparada do

Programa de Pós-Graduação em Letras: Estudos Literários da UFMG

(Belo Horizonte - MG)

RESUMO: O artigo faz uma leitura crítica da obra da poeta Auta de Souza, a partir de um corpus de poemas extraído de seu livro Horto (1900). Contrastamos a palavra poética de Auta de Souza com o que disse parte de sua fortuna crítica a respeito de sua obra, e observamos como essas leituras foram afetadas por vi sões distorcidas acerca da autoria feminina e por mitos culturais a respeito da "poeta mulher" vigentes no século XIX. Tenciona-se discutir aspectos da poesia da autora que passaram despercebidos pela fortuna crítica - tais como sua musicalidade, seu caráter moderno e sua temática homoerotica. Esses elementos parecem ter sido ignorados pela fortuna critica devido a uma mistura inadequada entre as personas poéticas construídas pela escritora a pessoa empírica da poeta, com sua trajetória pessoal e biográfica.

RÉSUMÉ L'article fait une lecture de l'œuvre littéraire de la poétesse Auta de Souza, en utilisant un corpus de poèmes de son livre Horto (1900). Le texte fait un contraste entre le mot poétique d'Auta et les affirmations de sa critique sur son œuvre, et on obsèrve comment cettes lectures sont affectées par des distor sions sur des femmes écrivaines et par des mythes culturels sur la "poétesse" au XIXe siècle. L'article aussi a l'objectif de discuter des aspects de la poésie d'Auta que sa critique n'a pas discuté, à cause d'une mélange inadéquate entre les personnes poétiques et la personne empirique de l'écrivaine, avec sa narrative personnelle et biographique.

MOTS-CLÉS: Auta de Souza; poétesse; image; personne.

PALAVRAS-CHAVE: Auta de Souza; poeta; imagem; persona. 
Mais de quatro décadas passadas desde que Barthes decretou a "morte do autor" em 1968 (BARTHES, 1984), os problemas teórico-críticos que concernem à questão da autoria se multiplicam. Para quem se debruça sobre a poesia moderna, o fantasma do autor e as narrativas que revestem a sua vida parecem se recusar ao silêncio da pedra tumular. A questão é bastante fecunda para pensar a poesia de Auta de Souza - poeta da qual tentamos nos aproximar com a escrita deste artigo - sobretudo considerando que, a despeito de ter produzido uma obra nada irrelevante para a tradição lírica brasileira, a historiografia literária canônica parece insistir em sepultar seu nome de maneira indevida. Se o nome de Auta está morto, o fato não ocorreu sem prejuízos para a nossa História Cultural.

Talvez a pergunta nada inocente sobre "quem fala" e, sobretudo, "que diferença faz quem fala" em matéria de literatura deva ser invocada a partir do momento em que delimitamos o que estamos entendendo como o "autor" e sua "vida". No pior dos casos, o espectro do autor faz toda a diferença. Talvez pudéssemos dizer, com o crítico norteamericano Lawrence Lipking, que a poesia "não pode nos dizer se o autor era uma pessoa feliz, ou um pecador, ou politicamente justificável, ou se sofria de pesadelos; mas pode nos revelar tudo o que precisa mos saber sobre a habilidade do autor de converter sua experiência em uma visão" (LIPKING, 1981, p. 10, tradução nossa). ${ }^{1}$

Não se deve, contudo, ignorar a importante inversão autorizada por Barthes, quando remove do "autor" a, até então, inatacável autoridade. Decretar a morte do autor implicava, no contexto de Barthes, uma abertura do texto para outras figuras que, até então, haviam passado despercebidas pela crítica literária, que confiava no "autor" para conferir um sentido último e totalizante aos textos. Barthes efetiva, é verdade, uma mirada importante sobre o texto "em si" e sua dimensão propriamente linguístico-material, seu caráter de enunciado, o que foi fundamental para abandonar a obsessão biografista que atravessou a crítica literária durante muito tempo.

Em suma: remover o autor da centralidade da discussão sobre o texto literário foi um movimento muito importa nte no sentido de romper com a pesada tradição da crítica biográfica que estabelecia uma relação teleológica entre "vida do autor", ou, mais especificamente, dentro do recorte desse artigo, entre a "vida do poeta" e "sua obra". Mas não estava ainda claro para Barthes - talvez até pelo imperativo radical da ruptura, que obriga a saídas sem mediações e meios-termos - que a investida sobre o "objeto texto literário" não deveria implicar, necessaria mente, a abolição da categoria "autor".
1. "Poetry cannot tell us wheter the author was a happy person, or a sinner, or justified in his politics, or suffering from bad dreams but it can tell us all we need to know about the author's ability to convert his experience into vision $[\ldots]^{\prime \prime}$. 
2. "Yet no poet becomes himself without inheriting an idea of what it means to be a poet. [...] If the lives of the poets tend to be peripheral to the insides of poems, the life of the poet is often the life of the poem." 3. "In order to teach us how first project himself inust first project himself into his
work $[. . .]^{\prime}$.
Existem outras maneiras pelas quais a crítica pode apelar à questão da "autoria" sem estabelecer uma relação de causa e efeito imediata entre a "vida do poeta" e a "obra do poeta", e sem a tribuir necessariamente uma obra literá ria excepciona à vida de um sujeito genial e de exceção. Nesse sentido, poderíamos pensar menos em termo da vida biográfica propriamente dita e mais numa vida de poeta "construída". Ainda com Lipking, poderíamos dizer a esse respeito que "nenhum poeta se torna ele mesmo sem herdar uma ideia do que significa ser poeta" e que, "se as vidas dos poetas tendem a ser periféricas à interioridade dos poemas, a vida do poeta é frequentemente a vida do poema" (LIPKING, 1981, p. 8-9, tradução nossa). ${ }^{2}$

Trata-se, é verdade, de uma "vida de poeta" inventada e autoconsciente, já que, "para nos ensinar como vê-lo, o poeta deve em primeiro lugar projetar a si mesmo em seu trabalho" (LIPKING, 1981, p. 9, tradução nossa). ${ }^{3}$ O que Lipking tenciona dizer é que, no âmbito da crítica literária, muito mais importante do que a "vida biográfica" de um poeta é a vida testemunhada por seus poemas, que sugere uma certa ideia de "vocação", "carreira" e "destino", e que conduz o leitor a uma imagem ou multiplicidade de imagens que o poeta deseja projetar a respeito de si mesmo. Essas imagen podem, inclusive, constituir personas e vozes poéticas muito distintas da pessoa empírica do autor. Esta constatação nos parece acertada na medida em que torna mais complexa a relação entre "autor" e "texto", mas sem abdicar de todo da categoria "autor".

Indo ainda um pouco mais longe que Lipking e nos distanciando ainda mais de um close-reading, sem, no entanto, cair nas tentadoras simplificações de um biografismo crítico, poderíamos recorrer às reflexões da crítica russa Svetlana Boym, em seu interessante trabalho Death in quotation marks (BOYM, 1991). Ao utilizar a expressão "morte entre aspas" death in quotation marks), Boym faz uma brincadeira irônica com a ideia da "morte do autor", que, em seu livro, é evocada em sua literalidade, não no sentido discursivo barthesiano. Boym reflete acerca da recepção de quatro mortes (literais e biográficas) de poetas muito distintos, ${ }^{4}$ a fim de investigar o que ela chama de "mitos culturais" a respeito da figura desses poetas, ou seja, as narrativas e o imaginário construído a respeito desses poetas na esfera pública, que podem, ou não, coincidir com as imagens que o poeta tentou construir de si mesmo. Sobre a questão, Boym chega a afirmar, na introdução de seu livro, que "[a] tensão e a interdependência entre literatura e vida constitui a aporia central da modernidade" (BOYM, 1991, p. 9, tradução nossa). ${ }^{5}$

Feitas essas considerações a respeito do problema da "autoria" e de suas implicações no estudo da poesia moderna, dispomos de mais ferramentas metodológicas para uma
4. As mortes e poéticas em questão são dos franceses Mallarmé e Rimbaud e dos russos Maiakóvski e Tsvetáieva.

5. "The tension and interdependence of literature and life constitutes the central aporia of modernity $[\ldots]^{\prime \prime}$. 
leitura crítica da poeta que esse artigo se propõe a a nalisar. O fato de ser "uma poeta", em detrimento de "um poeta", parece, ainda, ser muito significativo para o debate acerca do problema da "autoria".

O exercício de crítica sobre a poesia produzida por mulheres é uma tarefa custosa. Por todos os lados, corre-se o risco de se enveredar por simplificações reducionistas. Há o risco de, ao se tentar pensar a poesia de autoria feminina, ignorar o que deveria ter centralidade: a própria poesia. $\mathrm{Ou}$ seja, ignorar tudo o que seja parte de artifícios e construtos poeticamente elaborados, para deter-se no que se crê ser algo inerente a uma "escrita feminina", quase que uma busca por uma espécie de misteriosa quintessência que subsumisse tudo o que atravessa a ideia de "ser mulher". Sob este prisma, a poesia de autoria feminina fica reduzida ao que pode revela sobre uma imprecisa condição de feminilidade, e, portanto, há um rol muito limitado de tópicos passíveis de serem poetizados pelas mulheres, ou dignos de atenção por parte da crítica, uma vez poetizados.

Dito isso, não se pode ignorar a existência da rea dificuldade - cuja gênese é política, histórica e social de inclusão das mulheres autoras na esfera pública e nos meios literários. Para quem se debruça sobre a literatura oitocentista, o fenômeno da exclusão das mulheres da esfera pública é relevante para a crítica literária não apenas como elemento exterior à literatura, não apenas como curiosidade histórico-sociológica, mas como elemento tão determinante e significativo que se torna, ele mesmo, matéria de poesia. É importante esclarecer que a utilização do termo "oitocentista", nesse texto, se dá efetivamente entre aspas, com a consciência das limitações teóricometodológicas de um recorte meramente "cronológico" e "temporal" da literatura, mas se justifica, em parte, pela cômoda abrangência de produções estético-literárias que a categoria "oitocentista" comporta, e, em parte, porque a poeta que o artigo tenciona investigar insere-se num contexto oitocentista finissecular que se torna irredutível a ideias muito ortodoxas e - em certo sentido - a nacrônicas sobre o que seja um "estilo de época".

Delimitadas as insuficiências do emprego da palavra "oitocentista", cabe observar que os problemas advindos da autoria feminina no século XIX aparecem, por vezes, de maneira pontual num poema, quase como que à revelia da própria autora, traindo uma certa ideia a respeito de si mesma e a respeito do seu lugar no mundo enquanto poeta. Considere-se, por exemplo, o primeiro verso do poema "Uma carta de mulher", da poeta romântica francesa Marceline Desbordes-Valmore, em tradução de Sandra Stroparo e Caetano W. Galindo (DESBORDESVALMORE, 2016): 
As mulheres, eu sei, não devem escrever;

Mas ouso a arte,

Pra que em meu coração de longe possas ler

Como quem parte.

A dicção romântico-confessional do poema atende a todos os cacoetes estilísticos da época, mas o que salta aos olhos do leitor é uma certa autoconsciência da voz lírica - que se sabe mulher e poeta - e, de certa maneira, parece desculpar-se por ousar um ofício tão deslocado das atribuições feminina socialmente aceitas no século XIX. Feitas as devidas ressalvas, segue a carta "de mulher" a um objeto a moroso idealizado que lhe seria destina tá rio, fonte inesgotável de alegria e desejo de abnegação do sujeito poético. Mas, muito mais do que testemunho-confessional, o poema também se revela como um interessante registro acerca da autoconsciência da poeta sobre o exercício da escritura, conforme é possível verificar na segunda estrofe:

Qualquer beleza que existir em minha escrita Mostraste antes

Mas soa nova a palavra cem vezes dita,

Quando entre amantes.
É bastante curiosa e signo de modernidade esta autoconsciência da poeta acerca de si mesma e de seu lugar de mulher que edifica uma voz lírica num cenário cultural majoritariamente masculino. No caso de Marcelline Desbordes-Valmore, a situação se torna ainda mais interessante, na medida em que a autora passa a ser integrada por poetas-homens ao próprio imaginário do "poeta maldito" e "decadente". Verlaine a insere no livro Les poètes maudits e é introduzido à poesia de Valmore por Rimbaud, que consegue identificar na autora algumas afinidades com Baudelaire. ${ }^{6}$ Esta identificação da poeta ao imaginário do "poeta maldito" do século XIX é particularmente fecunda se pensarmos que, a princípio, a maioria das mitos culturais construídos a respeito do poète maudit no século XIX são majoritariamente masculinos ou versam sobre poetas-homens.

Alguns anos mais tarde, e em um cenário históricocultural bastante distinto da França oitocentista, no Brasil, na cidade de Macaíba, no Rio Grande do Norte, nasceria a poeta Auta de Souza. Auta começaria a poetar em 1893 annus mirabilis para a literatura brasileira, com o potente milagre verbal da publicação de Broquéis, de João da Cruz e Sousa, marco da literatura simbolista no Brasil.
6. Cf texto da professora Sandra Stroparo (2016). 
Seu primeiro e único livro publicado em vida - Horto - sairia em 1900, e não é redutível a nenhuma ideia mais obsoleta do que seja um estilo de época: mistura de poesia místicoespiritualista de dicção simbolista, temas românticos universais (como a morte e a nostalgia da infância) e poemas de expressão clara e simples que encontraram repercussão no cancioneiro popular. Embora Horto tenha sido sucesso de vendas a seu tempo, sua legitimação crítica parece ter vindo a despeito dos virtuosismos da própria poeta.

Nos prefácios às três edições iniciais do Horto respectivamente de 1900, 1905 e 1936 - uma série de temas e nuances da poesia de Auta são sistematica mente ignorados em nome de tornar toda a sua poética redutível a uma poesia mística de viés cristão, que seria explicável pela sua educação religiosa num colégio de freiras vicentinas no Recife. Antípoda da imagem de um poeta-herói romântico byrônico, ou do imaginário a respeito do poeta decadentista finissecular, o imaginário construído a respeito da mulher empírica Auta de Souza, impregnado de um ideário de pureza arcangélica e ascese cristã, parece ter se projetado sobre sua poesia e tornado boa parte da fortuna crítica incapaz de localizar os elementos poéticos e metapoéticos desviantes do que se parecesse com um missal.

No prefácio à primeira edição, assinado por Olavo Bilac, o que, a princípio, seriam menções elogiosas à poeta, hoje nos soam como demérito ou característicos de uma poesia ingênua e irrefletida. Curioso que o a utor de "Profissão de Fé" tenha dito a respeito de Auta que "não há nas estrofes de Horto o labor pertinaz de um artista" ou que "aqui a Alma vibra em liberdade, sem a preocupação dos enfeites da forma", livre "da complicada teia do artifício” (BILAC, 2009, p. 29). Por fim, o livro traria uma "simples e ingênua sinceridade". Difícil crer que o eleito "príncipe dos poetas brasileiros" efetivamente acreditasse, a despeito do empenho parnasiano e da sua profissão de fé, que uma poesia "simples" e "sem labor" pudesse ser de um "encanto crescente" (BILAC, 2009, p. 30). A única explicação possível para a estranheza do prefácio elogioso é que as expectativas de Bilac enqua nto leitor fossem reduzidas pelo fato de se tratar de uma mulher que "não deve escrever".

Mesmo o prefácio de a utoria do irmão de Auta de Souza, na segunda edição do livro, em 1905, já datados quatro anos da morte precoce da autora, por tuberculose, trai um olhar crítico algo condescendente com uma certa "pureza" e "santidade" que poderiam ser extraídos do livro e que denotariam uma "pureza" e "santidade" da própria Auta, cuja trajetória escolar foi construída num colégio de freiras vicentinas no Recife. Independentemente de a mulher empírica - que não era de todo, mas o era em grande parte, contemplada pelo epíteto de poeta - ter sido efetivamente uma cristã praticante, o apreço pela experiência mística não é capaz de explicar toda 
a sua produção literária, mesmo a que tematiza experiências espirituais de ascese cristã.

Há em Auta também uma nota muito aguda de melancolia pessimista de matriz romântica, como no dramático "Nunca mais", que conta com epígrafe lamuriosa de Lamartine. Um elemento de tensão agônica atravessa o poema, curiosamente ignorado pela leitura crítica do próprio irmão, que, no prefácio à segunda edição do Horto, parece misturar o temperamento da mulher e da poeta, estranhando que Auta se encantasse pelos "versos tumultuosos de Luiz Murat" (CASTRICIANO, 2009 , p. 34), a final sua alma era "meiga, tão cheia de religiosa ternura" e, portanto, incompatível com o "tumultuoso na literatura” (CASTRICIANO, 2009, p. 34).

A a firmativa de seu irmão Henrique Castriciano parece ecoar no posterior prefácio de Alceu Amoroso Lima que chega a afirmar que os versos de Auta de Souza demonstram como a poeta "viveu em estado de graça" e que a tristeza da poeta não consistia na "tristeza do desespero", de que seria separada por "uma noção viva e constante do mundo sobrenatural" (LIMA, 2009, p. 37). Mas é justamente esta mesma tristeza "do desespero", da agonia da morte iminente e de uma certa "noite obscura da alma" que desponta em "Nunca mais", como é possíve verificar nas duas estrofes finais:
Meu casto sonho! Lá se foi cantando,

Talvez em busca de uma pátria nova.

Deixou-me o coração como uma cova,

E, dentro dele, o meu amor chorando.

Nunca mais voltará... Pois, que lhe importa?

Esta morada lúgubre e sombria?

Não pode agasalhar uma alegria

Minh'alma, pobre morta! (SOUZA, 2009, p. 106).

É válido, por fim, destacar um último aspecto da poesia de Auta que parece terreno fértil, porém ainda inexplorado pela fortuna crítica. Refiro-me à até bastante explícita construção de vozes poéticas que apontam para uma dicção homoerótica. É curioso que a dimensão do homoerotismo tenha sido localizada e discutida pela fortuna crítica a respeito de um poeta como Junqueira Freire, que se vincula a uma experiência real de religiosidade de maneira muito mais aguda que a de Auta, haja vista que foi atravessada pela vivência do claustro. A crítica conseguiu muito bem localizar a dimensão do homoerotismo na poesia oitocentista e romântica de Junqueira Freire, com o seu apreço pela idealização a morosa de mancebos "adorados" e inacessíveis, como no famoso "Eu que te amo tão deveras", ou na ambiguidade que salta aos olhos nas descrições andróginas de figuras angelicais dignas 
de adoração, como sugere essa estrofe do adorável poema "Que temes?":

Temes que os homens conheçam

Que és tu só meu serafim?

Temes que os homens nos vejam

Tão abraçados assim?

Temes que os homens invejem

Nossa ventura por fim? (FREIRE, 1970, p. 6)

Em Auta de Souza, a insinuação de um discurso homoerótico feminino é multifacetada. Não se envolve tanto numa atmosfera de mistério e interdito, como o tratado em Junqueira Freire. Pelo contrário, insinua-se de maneira simples e desavergonhada, e causa no leitor vá rias expressões interroga tivas, principalmente quando a voz poética descreve uma figura feminina passível de idealização e adoração, mas o poema consta com uma dedicatória da própria autora para alguma mulher. Evidentemente, não nos cabe, como leitores - ao menos se tenciona mos não incorrer nos deslizes de um certo biografismo crítico -, especular acerca da questão na vida da autora empírica. O que efetivamente viveu Auta não nos cabe descrever, mas as múltiplas vozes líricas que a poeta constrói para tratar do tópico é de interesse crítico-literário.
O tratamento às vezes conta com uma voz poética que flerta com olúdico, com versinhos de cadência simples e muito sonora, como na sextilha "As mãos de Clarisse" (SOUZA, 2009, p. 99):

\section{Causam-me tantos martírios \\ As tuas mãos adoradas, \\ Com estes dedos de fadas, \\ Tão formosos e pequenos \\ Que eu chamaria de lírios, \\ Se houvesse lírios morenos!}

Ainda nesse sentido podemos recorrer ao poema "Morena" (SOUZA, 2009, p. 79) - que consta com a dedica tória "À moça mais bonita de minha terra” -, em dúcteis versos musicais que evocam a canção popular e sugerem a simplicidade eufônica de "A valsa", de Casimiro de Abreu:

Ó moça faceira,

Dos olhos escuros,

Tão lindos, tão puros,

Qual noite fagueira! 
Os olhos descritos são caracterizados como "santos", na terceira estrofe, mas, a despeito de uma certa mansidão arcangélica da figura descrita, o encanto sedutor é muito claro:

E eu vivo adorando,

Meu anjo formoso,

O brilho radioso

Que vão derramando,

Em chamas serenas,

Tão mansas e puras,

Teus olhos escuros,

Ó flor das morenas.

O arsenal de figuras femininas caracterizadas pelos olhos observadores de uma voz lírica muito atenta - e, minimamente, curiosa - é gigantesco. O tratamento é, por vezes, de uma certa devoção, como se a mulher contemplada traísse semelhança com alguma figura sacra. Mas há uma descida interessante ao rés-do-chão em alguns poemas particularmente interessantes. Em "Versos Ligeiros" (SOUZA, 2009 , p. 84), por exemplo, a voz poética parece empenhada em mostrar que se presta a escrever um poema de circunstância.
A escolha lexical é pouco idealista e a própria figura feminina descrita tem nome - mui prosaico:

Eu acho tão feiticeira

A Noemita da esquina,

Com o seu recato de freira,

Muito morena e franzina [...]

O desfecho do poema passa longe do idealismo romântico e ainda mais longe de um discurso místico-cristão. Esbarra mesmo num discurso cômico ou de tom chistoso:

\section{É verdade que não faz}

Mal nenhum fitá-la assim...

Meu Deus! Se eu fosse rapaz

$\mathrm{O}$ que diria $\mathrm{m}$ de mim?

Podemos citar ainda alguns poemas cuja subjetividade lírica descreve notas sentimentais mais complexas. Em "Olhos de Santa" (SOUZA, 2009, p. 100), a escolha lexical é menos informal, flerta com um discurso sobre o sublime, ou até mesmo com uma contemplação mística e sacralizada 
da mulher adorada, o que, no entanto, não suprime a verve homoerótica:

Cheios de treva e luz, teus olhos têm a cor Das noites sem luar, ó meu divino amor! E eu amo tanto a sombra e o brilho doce e puro Dos grandes olhos teus, ó luz de meu futuro, Como adora minh'alma os rútilos clarões Do bando virginal de suas ilusões.

O vocativo que se segue - "Querubim piedoso" - semelha os poemas de Junqueira Freire dedicados aos serafins andróginos. A idealização não é, no entanto, marcada pelo signo do impossível ou do inacessível, como atesta a última estrofe, em que consta o verso "Uma estrela se fez do nosso a mor sem fim”. O tom chistoso e brincalhão, porém, aparece novamente em outros poemas. No engraçado "No álbum de Dolores" (SOUZA, 2009, p. 123), os desenganos amorosos e a autocomplacência da voz lírica frente ao objeto amoroso desejado esbarram na autoironia:

Escuta-me bem, Dolores,

Não queiras meu nome aqui:
Ele não é colibri

Para viver entre flores.

$[\ldots]$

Meu triste nome choroso

Quer uma outra habitação,

Guarda-o no coração,

Lírio celeste e formoso.

As abordagens do tema são múltiplas e revela m um trabalho consciente de construção da poesia e de vozes líricas/personas poéticas distintas. Todos esses poemas têm contudo, algo em comum, que inclusive partilham com quase todos os poemas que formam a arquitetura de Horto: passam muito longe de uma poesia ingênua e irrefletida, são o produto consciente de uma poeta-artífice e, contraria mente às constatações de Bilac, produto do "labor pertinaz de uma artista" que se reconhece como tal.

Não por acaso, como uma espécie de mirada mágica e intuitiva sobre o destino de sua obra, escolhe a autora como uma de suas epígrafes uma estrofe da "Dedicatória", poema de abertura das Espumas Flutuantes, de Castro Alves (figura que representa, por excelência, o arquétipo do "gênio romântico" aspirante à glória literária). Cito a epígrafe: 
Os túmulos dos teus dão-te regaços! Ama-te a sombra do salgueiro aflito..

Vai, pois, meu livro! E como o corvo agreste

Traz-me, no bico, um ramo de cipreste!

Trata-se, com efeito, de uma apóstrofe algo mórbida trágica, mas atravessada por sincero entusiasmo e desejo de consagração como uma voz cantante e autônoma dentre outras vozes potentes na poesia brasileira.

\section{REFERENCIAS}

BARTHES, Roland. La mort de l'auteur. In: Le bruissement de la langue. Paris: Éditions du Seuil, 1984. p. 61-67

BILAC, Olavo. Prefácio da $1^{\text {a }}$ edição do Horto. In : SOUZA, Auta de. Horto, outros poemas e ressonâncias: obras reunidas. Natal: EDUFRN, 2009. p. 29-31.

BOYM, Svetlana. Death in quotation marks: cultural myths of the modern poet. Cambridge: Harvard University Press, 1991.
CAMILO, Vagner. Da sátira obscenaao axioma do frei: poesia romântica e homoerotismo no Brasil (1850-1864). Journal of Lusophone Studies, Special Dossier on Transnational and Counternational Queer Agencies in Lusophone Cultures, v. 4, n. 1, 2019. Disponível em: <https://jls.apsa.us/index.php/jls/article/view/297> . Acesso em: 27 nov. 2019.

CASTRICIANO, Henrique. Nota da $2^{a}$ edição do Horto. In: SOUZA Auta de. Horto, outros poemas e ressonâncias: obras reunidas. Natal: EDUFRN, 2009. p. 33-35.

DESBORDES-VALMORE, Marcelline. Uma carta de mulher. Escamandro, 2016. Tradução de Sandra Stroparo e Caetano Galindo. Disponível em < https://escamandro.wordpress.com/2016/10/14/ marceline-desbordes-valmore-1786-1859-por-sandra-stroparocaetano-w-galindo/>. Acesso em: 27 nov. 2019.

FREIRE, Junqueira. Inspirações do claustro. Salvador: Editora Janaína, 1970.

LIMA, Alceu Amoroso. Prefácio da $3^{a}$ edição. In: SOUZA, Auta de. Horto, outros poemas e ressonâncias: obras reunidas. Natal: EDUFRN, 2009. p.37-38.

LIPKING, Lawrence. The life of the poet: Beginning and ending poetic careers. London: The University of Chicago Press, 1981. 
SOUZA, Auta de. Horto, outros poemas e ressonâncias: obras reunidas. Natal: EDUFRN, 2009.

STROPARO, Sandra. Marceline Desbordes-Valmore (1786-1859),

por Sandra Stroparo \& Caetano W. Galindo. Disponível em: $<$ https://escamandro.wordpress.com/2016/10/14/marcelinedesbordes-valmore-1786-1859-por-sandra-stroparo-caetano-wgalindo/>. Acesso em: 27 nov. 2019.

Recebido em: 28-11-2019.

Aceito em: 28-03-2020 